\title{
Cathode encapsulation of organic light emitting diodes by atomic layer deposited $\mathrm{Al} 2 \mathrm{O} 3$ films and Al2O3/a-SiNx: $\mathrm{H}$ stacks
}

Citation for published version (APA):

Keuning, W., Weijer, van de, P., Lifka, H., Kessels, W. M. M., \& Creatore, M. (2012). Cathode encapsulation of organic light emitting diodes by atomic layer deposited Al2O3 films and Al2O3/a-SiNx: $\mathrm{H}$ stacks. Journal of Vacuum Science and Technology A: Vacuum, Surfaces, and Films, 30(1), 01A131-1/6. [01A131].

https://doi.org/10.1116/1.3664762

DOI:

10.1116/1.3664762

Document status and date:

Published: 01/01/2012

Document Version:

Publisher's PDF, also known as Version of Record (includes final page, issue and volume numbers)

Please check the document version of this publication:

- A submitted manuscript is the version of the article upon submission and before peer-review. There can be important differences between the submitted version and the official published version of record. People interested in the research are advised to contact the author for the final version of the publication, or visit the $\mathrm{DOI}$ to the publisher's website.

- The final author version and the galley proof are versions of the publication after peer review.

- The final published version features the final layout of the paper including the volume, issue and page numbers.

Link to publication

\footnotetext{
General rights

- You may freely distribute the URL identifying the publication in the public portal. follow below link for the End User Agreement:

www.tue.nl/taverne

Take down policy

If you believe that this document breaches copyright please contact us at:

openaccess@tue.nl

providing details and we will investigate your claim.
}

Copyright and moral rights for the publications made accessible in the public portal are retained by the authors and/or other copyright owners and it is a condition of accessing publications that users recognise and abide by the legal requirements associated with these rights.

- Users may download and print one copy of any publication from the public portal for the purpose of private study or research.

- You may not further distribute the material or use it for any profit-making activity or commercial gain

If the publication is distributed under the terms of Article $25 \mathrm{fa}$ of the Dutch Copyright Act, indicated by the "Taverne" license above, please 


\title{
Cathode encapsulation of organic light emitting diodes by atomic layer deposited $\mathrm{Al}_{2} \mathrm{O}_{3}$ films and $\mathrm{Al}_{2} \mathrm{O}_{3} / \mathrm{a}-\mathrm{SiN}_{\mathrm{x}}: \mathrm{H}$ stacks
}

\author{
W. Keuning \\ Department of Applied Physics, Eindhoven University of Technology, P.O. Box 513, 5600 MB Eindhoven, \\ The Netherlands \\ P. van de Weijer and H. Lifka \\ Philips Research Laboratories, High Tech Campus 4, P.O. Box WAG12, 5656 AE Eindhoven, The Netherlands \\ W. M. M. Kessels and M. Creatore ${ }^{\text {a) }}$ \\ Department of Applied Physics, Eindhoven University of Technology, P.O. Box 513, 5600 MB Eindhoven, \\ The Netherlands
}

(Received 18 August 2011; accepted 8 November 2011; published 5 December 2011)

\begin{abstract}
$\mathrm{Al}_{2} \mathrm{O}_{3}$ thin films synthesized by plasma-enhanced atomic layer deposition (ALD) at room temperature $\left(25^{\circ} \mathrm{C}\right)$ have been tested as water vapor permeation barriers for organic light emitting diode devices. Silicon nitride films $\left(\mathrm{a}-\mathrm{SiN}_{\mathrm{x}}: \mathrm{H}\right)$ deposited by plasma-enhanced chemical vapor deposition served as reference and were used to develop $\mathrm{Al}_{2} \mathrm{O}_{3} / \mathrm{a}-\mathrm{SiN}_{\mathrm{x}}: \mathrm{H}$ stacks. On the basis of $\mathrm{Ca}$ test measurements, a very low intrinsic water vapor transmission rate of $\leq 2 \times 10^{-6} \mathrm{~g} \mathrm{~m}^{-2}$ day $^{-1}$ and $4 \times 10^{-6} \mathrm{~g} \mathrm{~m}^{-2}$ day $^{-1}$ $\left(20^{\circ} \mathrm{C} / 50 \%\right.$ relative humidity) were found for $20-40 \mathrm{~nm} \mathrm{Al}_{2} \mathrm{O}_{3}$ and $300 \mathrm{~nm}$ a-SiN $\mathrm{S}_{\mathrm{x}}: \mathrm{H}$ films, respectively. The cathode particle coverage was a factor of 4 better for the $\mathrm{Al}_{2} \mathrm{O}_{3}$ films compared to the a-SiN $\mathrm{x}: \mathrm{H}$ films and an average of 0.12 defects per $\mathrm{cm}^{2}$ was obtained for a stack consisting of three barrier layers $\left(\mathrm{Al}_{2} \mathrm{O}_{3} / \mathrm{a}-\mathrm{SiN}_{\mathrm{x}}: \mathrm{H} / \mathrm{Al}_{2} \mathrm{O}_{3}\right)$. C 2012 American Vacuum Society. [DOI: 10.1116/1.3664762]
\end{abstract}

\section{INTRODUCTION}

The applicability of organic light emitting diodes (OLEDs) is versatile and ranges from displays for mobile devices and TV screens to large scale solid state lighting and, ultimately, to flexible displays. ${ }^{1-3}$ Thin film barrier encapsulation is investigated in order to replace the current capping method with the aim to reduce the weight, costs, and amount of materials used. This represents a very challenging part in the development of OLEDs which is essential for further development of flexible devices. The requirement on the maximum allowed water vapor transmission rate (WVTR) of $10^{-6} \mathrm{~g} \mathrm{~m}^{-2}$ day $^{-1}$ is yet very demanding for thin film water vapor barriers to date. A barrier of that quality can ensure an OLED shelf lifetime larger than $10 \mathrm{yr},{ }^{1,4}$ provided that it does not have defects. These pinholes or defects in the encapsulation can cause the creation nonemissive black spots that significantly reduce the lifetime of an OLED, as it will be addressed in detail below. ${ }^{5}$ In our current research we focus on solid state lighting, which requires the encapsulation of OLEDs with a size of about one square meter without any visible, nonemissive black spots.

Briefly, a typical OLED structure consists of an organic semiconductor, sandwiched between two electrodes: ${ }^{6}$ the anode is a transparent conductive oxide (TCO), while a low work function metal (e.g., barium or calcium) is typically used as cathode. These materials are very sensitive to water and prone to oxidation, and therefore capped by aluminum, which is an excellent water vapor permeation barrier layer. However, it is locally defective (with a defect density in the range of $10^{3}-10^{5} \mathrm{~cm}^{-2}$ ) mainly because of the generation

\footnotetext{
a) Author to whom correspondence should be addressed; electronic mail: m.creatore@tue.nl
}

of particles during the processing of the organic semiconductor layer. ${ }^{4}$ Water vapor can therefore permeate through the defects in the aluminum layer, inducing local oxidation into the cathode and preventing charge injection at the interface with the organic semiconductor. The oxidized places on the cathode are visually identified by the development of nonemissive (black) spots. ${ }^{4}$ In conclusion, the application of a water vapor permeation barrier that is able to encapsulate the defects on the cathode surface of the device is mandatory.

In principle a single inorganic layer is sufficient to guarantee an intrinsic barrier performance (i.e., barrier performance far from regions where defects are present) of $10^{-6} \mathrm{~g} \mathrm{~m}^{-2}$ day $^{-1}$, which assures no cathode deterioration for $10 \mathrm{yr}$. However, less straightforward is the engineering of the inorganic layer when also addressing the local coverage of defects: in the presence of a single barrier layer, the density of the uncovered pinholes is still in the order of $10 \mathrm{~cm}^{-2}$, massively hampering the device operation. From this discussion it can be concluded that, next to the demand in ultrahigh barrier performances, pinhole encapsulation is also mandatory for the decrease and control of the local black spot development.

In this respect, atomic layer deposition (ALD) is of interest as it is a technique which is known for its conformal deposition over 3D structures and its high quality films synthesized at low temperature. ${ }^{7-9}$ It is therefore plausible to choose ALD to conformally cover of the particles responsible for the pinholes present on the cathode. Several studies have already shown that $\mathrm{Al}_{2} \mathrm{O}_{3}$ synthesized by ALD is a promising candidate for OLED encapsulation, ${ }^{10-17}$ however in these contributions the focus is on the engineering of barrier layers on polymer substrates. In the present work, we evaluate the inorganic barrier films in terms of intrinsic barrier performance as well as in terms of particle/defect conformal coverage 
directly on OLED devices. Next to the evaluation of single barrier layers of $\mathrm{Al}_{2} \mathrm{O}_{3}$ this contribution also addresses stacks of $\mathrm{Al}_{2} \mathrm{O}_{3}$ with a-SiN $\mathrm{x}: \mathrm{H}$ layers and stacks coupled to organic interlayers. A multilayer stack is often chosen to promote a better coverage of the pinholes as well as to promote a timedelay in black spot formation, ${ }^{18}$ as described below.

In Fig. 1 a schematic representation is given for the development of black spots. In Fig. 1(a) there is a defect in the inorganic barrier layer, but because this defect does not coincide with the defect in the $\mathrm{BaAl}$ cathode it does not lead to the growth of a black spot in the OLED. On the right side the defect in the cathode is well covered by the inorganic barrier and will also not be the cause for the development of a black spot, provided that the intrinsic WVTR of the barrier is low enough, as addressed earlier. In Fig. 1(b) the defects in the inorganic barrier layer and the $\mathrm{BaAl}$ cathode are coupled and will therefore lead to the creation of a black spot which grows linear in time. In Fig. 1(c) the inorganic barrier is covered by an organic film, which has negligible intrinsic barrier properties. Therefore, the water can permeate through that layer and subsequently via the defect in the inorganic layer and the cathode towards the interface between the organic semiconductor and the cathode. In Fig. 1(d) the cathode is covered by an inorganic-organic-inorganic barrier stack. This situation will still lead to the development of a black spot, but delayed in time. The delay time depends on the size of the defects, the distance between the two defects and the properties of the interlayer. The time delay should be very significant, with an aim of more than $10 \mathrm{yr}$, if the inorganic films have a low defect density.

In the experiments described in this article plasma enhanced ALD (PE-ALD) $\mathrm{Al}_{2} \mathrm{O}_{3}$ layers will be compared to state-of-the-art a- $\mathrm{SiN}_{\mathrm{x}}: \mathrm{H}$ layers deposited by plasma enhanced chemical vapor deposition (PE-CVD), which is one of the most adopted inorganic barrier/encapsulation layer. The

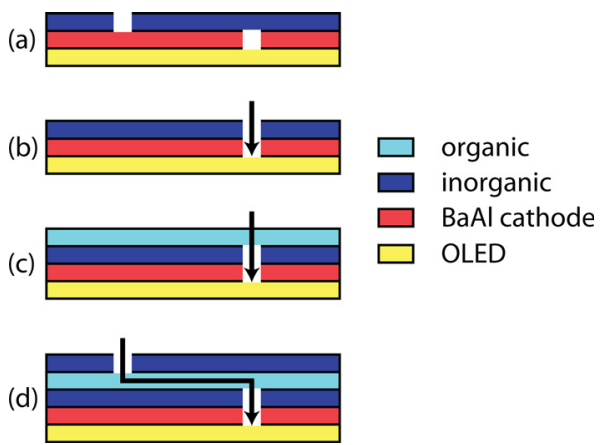

FIG. 1. (Color online) Schematic representation of water vapor permeation through defects in the encapsulation layer. (a) Successful encapsulation (under the hypothesis of an intrinsic barrier value of $10^{-6} \mathrm{~g} \mathrm{~m}^{-2}$ day $^{-1}$ ). The defect in the inorganic layer will not lead to black spots, while the defect in the cathode is well encapsulated. (b) A defect in the cathode propagates in the inorganic layer such that the water can reach the interface between the cathode and the organic semiconductor and cause a black spot. (c) Because the organic layer has no barrier properties, this case leads to a similar problem as in (b). (d) Defects are decoupled by an organic layer and the path length of water to reach the interface between the cathode and the organic semiconductor through the organic layer determines the time delay before the initiation of the black spot. intrinsic WVTR of the films were investigated by means of calcium test, and the number and size of defects in the encapsulation were studied with the films applied directly on top of the OLED cathode. Film stacks of $\mathrm{Al}_{2} \mathrm{O}_{3}$ and a-SiN $\mathrm{x}: \mathrm{H}$, with and without the application of an organic layer in those stacks, are investigated for their influence on the defect density in the encapsulation.

\section{EXPERIMENT}

\section{A. Thin film barrier deposition}

The synthesis of the PE-ALD films has been carried out in a FlexAL reactor of Oxford Instruments. The ALD cycle consisted of 4 steps: $\mathrm{Al}\left(\mathrm{CH}_{3}\right)_{3}$ (trimethylaluminum, TMA) dosing (20 ms), purge with $\mathrm{O}_{2}$ gas $(1.5 \mathrm{~s}), \mathrm{O}_{2}$ plasma (4 s), and purge with $\mathrm{O}_{2}$ gas $(0.5 \mathrm{~s})$. The $\mathrm{O}_{2}$ flow was constant throughout the whole cycle and only the TMA pulse was alternated as well as the plasma power. ${ }^{9}$ Since the organic semiconductor in the OLED cannot withstand temperatures higher than $110^{\circ} \mathrm{C}$ the deposition temperatures for the barrier layers were restricted to $110^{\circ} \mathrm{C}$ or lower. Because of this restriction PE-ALD was preferred over thermal ALD. ${ }^{8,19,20}$ All ALD layers presented here were deposited at $25^{\circ} \mathrm{C}$. The choice for deposition at room temperature was based on the results of our earlier work by Langereis et al. ${ }^{21}$ The TMA, which was kept at $30^{\circ} \mathrm{C}$, was dosed vapor drawn using fast Swagelok ALD valves. The remotely placed inductively coupled plasma (ICP) source, was operated at $400 \mathrm{~W}$. During the process the reactor was kept at a pressure of $15 \mathrm{mTorr}$. The resulting growth rate of this $\mathrm{Al}_{2} \mathrm{O}_{3}$ process was $0.17 \mathrm{~nm}$ per cycle. The material had a $[\mathrm{O}] /[\mathrm{Al}]$ ratio of 1.88 and contained $\sim 15$ at. $\%$ hydrogen. ${ }^{19,20}$ Both observations indicate the incorporation of a significant concentration of $\mathrm{OH}$-groups which was also observed experimentally in a separate study. ${ }^{21}$ More detailed information about the reactor and the $\mathrm{Al}_{2} \mathrm{O}_{3}$ process can be found elsewhere. ${ }^{19}$

The a-SiN $\mathrm{x}: \mathrm{H}$ films were deposited in a Plasmalab 800plus reactor of Oxford Instruments, which is a capacitively coupled parallel plate reactor driven at $13.56 \mathrm{MHz}$. For the deposition of a-SiN $\mathrm{x}: \mathrm{H}$, a plasma was generated in a $\mathrm{SiH}_{4} / \mathrm{N}_{2} / \mathrm{NH}_{3}$ mixture. For a substrate temperature of $110^{\circ} \mathrm{C}$ this resulted in stress free $(<80 \mathrm{MPa})$ a-SiN $\mathrm{x}: \mathrm{H}$ films with a hydrogen content of $20-30 \%$. The deposition rate was $0.5 \mathrm{~nm} / \mathrm{s}$ and the refractive index of the films was $n=1.90$. More details about the performance of the a-SiN $\mathrm{x}: \mathrm{H}$ films in barrier applications are reported elsewhere. ${ }^{4}$

A $20 \mu \mathrm{m}$ thick acrylate-based organic layer (Ixan-SGA-1 supplied by Solvay plastics) performed either as interlayer between two inorganic barriers or as top layer to improve the mechanical stability of the multistack. The organic material was brushed onto the sample and then left to dry. During this procedure the samples did not leave the glove box.

\section{B. Sample description and analysis}

The intrinsic barrier performances have been evaluated by means of the calcium test. ${ }^{22}$ The experiments were carried out following the approach and methodology described by 
Nisato et al. ${ }^{23}$ The substrates were $150 \times 150 \mathrm{~mm}$ glass plates covered by $40 \mathrm{~nm}$ Ca prepared by thermal evaporation. On top of the calcium $40 \mathrm{~nm} \mathrm{SiO}_{2}$ was deposited by PE-CVD which served as temporary barrier against moisture permeation during sample transportation. The $\mathrm{SiO}_{2}$ layer has no influence on the measurements since its WVTR was measured to be in the order of $10^{-2} \mathrm{~g} \mathrm{~m}^{-2}$ day $^{-1}$, while the ALD $\mathrm{Al}_{2} \mathrm{O}_{3}$ and the PE-CVD a-SiN $\mathrm{x}$ : $\mathrm{H}$ are three orders of magnitude better in terms of barrier performance, as will be discussed below. The Ca material has been deposited on the plates in a structure consisting of nine pads and each pad is divided in nine squares [see Fig. 2(a)], to avoid that the water vapor permeating through one defect would affect the whole area of the samples. When one of these squares showed a white spot (when $\mathrm{Ca}$ oxidizes it becomes transparent), as caused by a defect in the barrier film, that specific square was disregarded from the test. In such case the results of the rest of the squares were averaged to determine the intrinsic barrier performance of the inorganic layers. The $\mathrm{Ca}$ samples have been tested under $20^{\circ} \mathrm{C}$ and $50 \%$ relative humidity (RH) conditions.

The measurement setup for the calcium test (developed by Philips Research) consisted of a Philips CL5000M light source with a diffuser for uniform back lighting and a sample holder with mask. A 12 bit Adimex MX12p camera was used to obtain a gray scale image of the sample. The amount of oxidation is determined from the gray tint. A nontransparent black reference from the mask and a white reference from the transparent part of the glass plate have been included in every measurement to set the gray scale range and to correct for transparency changes due to the barrier film. This setup has been calibrated by performing an experiment where the calcium samples were measured on this setup and by Rutherford backscattering (RBS) simultaneously, and thus relating the optical transmission through the sample to the $[\mathrm{Ca}] /[\mathrm{O}]$ ratio in the samples. To obtain results with $10 \%$ precision the test should last until at least $1 \mathrm{~nm}$ of the $\mathrm{Ca}$ material has been oxidized. Since only the top $1 \mathrm{~nm}$ of metal $\mathrm{Ca}$ is oxidized in these experiments, it can be assumed that each $\mathrm{H}_{2} \mathrm{O}$ molecule reacts with one metal $\mathrm{Ca}$ atom to form $\mathrm{CaO}$ and that further oxidation to $\mathrm{Ca}(\mathrm{OH})_{2}$ does not occur yet.

In addition to the intrinsic barrier performance evaluation, the encapsulation of the local defects was studied by means of electroluminescence (EL) measurements carried out on OLEDs. These measurements have been performed at regular

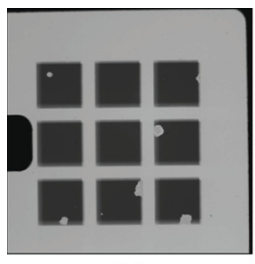

(a)

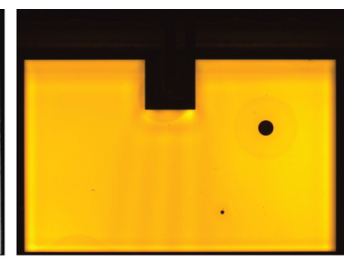

(b)
FIG. 2. (Color online) Photos of the (a) calcium sample and (b) OLED during electroluminescence measurements. The white spots on the calcium sample and the black spots on the OLED are due to water vapor permeation through defects in the encapsulation layer. intervals in time to register the quantity and size of the resulting nonemissive black spots [see Fig. 2(b)] as a function of time. For these experiments we have used OLEDs based on polymers. They have been synthesized on glass substrates of $150 \times 150 \mathrm{~mm}$ and on each substrate nine devices have been prepared, each device with an activated area of $6 \mathrm{~cm}^{2}$. Experiments were carried out on batches of four glass plates and to minimize effects of plate-to-plate variations, each barrier layer/stack was prepared on nine OLED devices distributed over three plates. A BaAl layer $(5 \mathrm{~nm} \mathrm{Ba}$ and $100 \mathrm{~nm} \mathrm{Al})$ has been used as a cathode. A more extensive description of the OLED stack can be found elsewhere. ${ }^{24}$

After encapsulation the OLED samples have been stored for shelf lifetime testing at $2{ }^{\circ} \mathrm{C}$ and $50 \%$ RH. For the EL measurements the OLEDs were temporarily removed from their controlled environment, switched on, and photos of the powered devices under operational conditions were taken. This process was repeated on regular basis, i.e., every day and once every week at later stages of the test. The EL photos were analyzed by imaging software to count the number of nonemissive black spots per device and to calculate the area of every black spot at that time. The detection limit for the software to recognize a black spot was $1000 \mu \mathrm{m}^{2}$.

For the black spot analysis we have used the following processing rules: a black spot is defined as visible when having an area larger than $0.01 \mathrm{~mm}^{2}$. To become visible within $10 \mathrm{yr}$ a black spot has to grow faster than $0.1 \mu \mathrm{m}^{2} / \mathrm{h}$; therefore all spots with a lower growth rate have been removed from the dataset. The application of this rule excluded for example the visible dust particles blocking the light and the defects that formed a black spot during processing but were encapsulated successfully by one of the layers in the stack. Furthermore, the imaging software took only circular black spots in a picture into account. This means that the size of a spot could no longer be calculated as soon as the spot merged with another spot or reached the edge of the OLED. In several cases this effect limited the number of data points for a black spot. Finally, all black spots with less than four data points have been excluded in order to filter out errors in the measurements caused by the analysis software. Because of these constraints in the analysis, it should be mentioned that a large scatter in the data is present, as will be addressed in Sec. III.

\section{Sample handling}

Sample handling was an important part of these experiments and it is therefore described in detail below. The OLED and calcium samples were produced by Philips Research in a glove box. Attached to this glove box was the Oxford Instruments Plasmalab 800plus tool which was used for the a-SiN $: \mathrm{H}$ and $\mathrm{SiO}_{2}$ synthesis. For the deposition of the $\mathrm{Al}_{2} \mathrm{O}_{3}$ films the samples had to be transported to the Eindhoven University of Technology (TU/e) with a travel time of approximately $30 \mathrm{~min}$. The samples were transported together with $\mathrm{Ca}$ getter material in a box under $\mathrm{N}_{2}$ atmosphere. After arrival at the TU/e the transport box and samples were immediately introduced into a glove box. In an 
exsiccator the samples were brought to the FlexAL reactor located in the TU/e clean room, where they were loaded through open air. After deposition the samples were placed back into the exsiccator, which was then evacuated and returned to the glove box. When all samples had been processed they were returned to Philips Research for further processing or to start the sample analysis.

\section{RESULTS AND DISCUSSION}

\section{A. Water vapor permeation through single layer barriers}

The importance to distinguish between intrinsic WVTR (water vapor permeation through the film in regions far from defects) and defects in the film has been stressed in the Introduction. In Fig. 3 a comparison is shown between the intrinsic WVTR values of the PE-ALD $\mathrm{Al}_{2} \mathrm{O}_{3}$, and the PE-CVD a-SiN $\mathrm{X}_{\mathrm{x}} \mathrm{H}$ films. For $\mathrm{Al}_{2} \mathrm{O}_{3}$, data is given for 20 and $40 \mathrm{~nm}$ thick films while the thickness of the a-SiN $\mathrm{x}_{\mathrm{x}}: \mathrm{H}$ film was $300 \mathrm{~nm}$. The test lasted for 70 days at $20^{\circ} \mathrm{C} / 50 \% \mathrm{RH}$ condition, before it had to be stopped since too many samples showed white spots indicating defects in the encapsulation. Over this period of time only $0.5 \mathrm{~nm}$ of $\mathrm{Ca}$ had been oxidized, which means that all layers that were subject to this test had an intrinsic WVTR in the $10^{-6} \mathrm{~g} \mathrm{~m}^{-2}$ day ${ }^{-1}$ range that is required for OLED encapsulation. Remarkable is that although the PE-ALD $\mathrm{Al}_{2} \mathrm{O}_{3}$ films are one order of magnitude smaller, they still show the same performance as the PE-CVD a-SiN $\mathrm{x}: \mathrm{H}$ films. Since the 20 and $40 \mathrm{~nm} \mathrm{Al}_{2} \mathrm{O}_{3}$ films show a similar WVTR value, we can conclude that thicker layers for the $\mathrm{ALD} \mathrm{Al}_{2} \mathrm{O}_{3}$ will not result in any further improvement of barrier properties.

ALD $\mathrm{Al}_{2} \mathrm{O}_{3}$ layers have been evaluated in terms of WVTR earlier in the literature. ${ }^{10,15,16,25,26}$ However, differences in test methods and testing conditions hamper a direct comparison, even in cases when similar Ca tests have been performed. For example, both Meyer et $a l .{ }^{25}$ and Carcia et al. ${ }^{26}$ conclude that their $\mathrm{Al}_{2} \mathrm{O}_{3}$ barrier films, which are synthesized by thermal ALD on polymer substrates, can reach values in the order of $10^{-6} \mathrm{~g} \mathrm{~m}^{-2}$ day $^{-1}$ at room temperature conditions. This confirms our results; however the best WVTR values

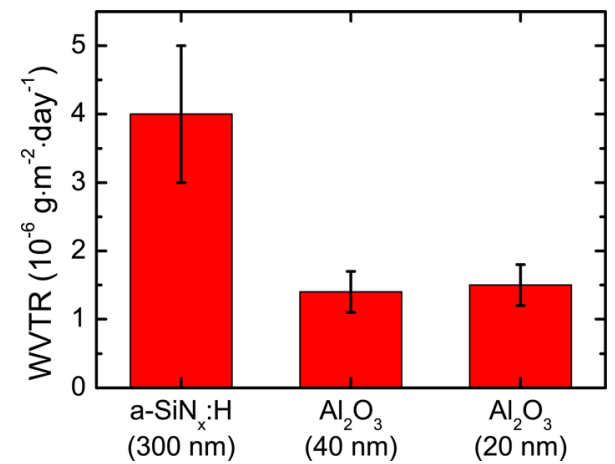

FIG. 3. (Color online) Intrinsic water vapor transmission rates (WVTR) measured for $300 \mathrm{~nm}$ a-SiN $\mathrm{x}: \mathrm{H}$ deposited by PE-CVD, 20 and $40 \mathrm{~nm}$ PEALD $\mathrm{Al}_{2} \mathrm{O}_{3}$. The layers have been deposited directly on the $\mathrm{SiO}_{2}$-covered calcium sample. The shelf lifetime has been tested at $20^{\circ} \mathrm{C} / 50 \% \mathrm{RH}$ and the test lasted for 70 days. reported by Meyer et al. were $3.5 \times 10^{-4} \mathrm{~g} \mathrm{~m}^{-2}$ day $^{-1}$, measured at $70^{\circ} \mathrm{C} / 70 \% \mathrm{RH}$ conditions for $100 \mathrm{~nm}$ thick films. Carcia et al. have reported a WVTR of $1.7 \times 10^{-5} \mathrm{~g} \mathrm{~m}^{-2} \mathrm{day}^{-1}$ under $38^{\circ} \mathrm{C} / 85 \% \mathrm{RH}$ conditions for $25 \mathrm{~nm}$ thick films, but indicated that their test values were limited by the epoxy which they used to glue the samples to the Ca substrates.

\section{B. Single layer encapsulation of OLED devices}

Since it has been shown that thin $\mathrm{ALD} \mathrm{Al}_{2} \mathrm{O}_{3}$ films do meet the requirement as barrier layer for OLED encapsulation in terms of intrinsic WVTR properties, the focus was shifted towards the size and density of defects and their encapsulation by the single layers. In Fig. 4 the results for single layer $\mathrm{Al}_{2} \mathrm{O}_{3}$ films have been compared with those for the a-SiN $\mathrm{N}_{\mathrm{x}}: \mathrm{H}$ film in terms of number of black spots per device and the average black spot growth rate. From the number of black spots, it can be concluded that the 20 and $40 \mathrm{~nm}$ ALD $\mathrm{Al}_{2} \mathrm{O}_{3}$ layers can effectively encapsulate the defects present on the cathode surface. They show better results than the $\mathrm{a}-\mathrm{SiN}_{\mathrm{x}}: \mathrm{H}$ reference, which is likely due to the higher conformality that is typical for films synthesized by ALD.

The average growth rate of the black spots is reported in Fig. 4(b). The ALD layers exhibit in general a higher black spot growth rate and this might indicate that the ALD encapsulation mechanism is mainly efficient for the small defects present at the surface. The ALD layer can leave the largest defects either uncovered or the layer itself could suffer from local stress around the large defects; therefore promoting an easier permeation path for water vapor to diffuse through the barrier layer. The thicker $\mathrm{a}-\mathrm{SiN}_{\mathrm{x}}: \mathrm{H}$ layer appears to perform better in terms of encapsulation of larger defects, which can be the results of the synergic combination of a larger thickness and a locally reduced stress. The comparison between the $\mathrm{ALD} \mathrm{Al}_{2} \mathrm{O}_{3}$ layers of 20 and $40 \mathrm{~nm}$ showed that the devices encapsulated with $20 \mathrm{~nm}$ films leaves more

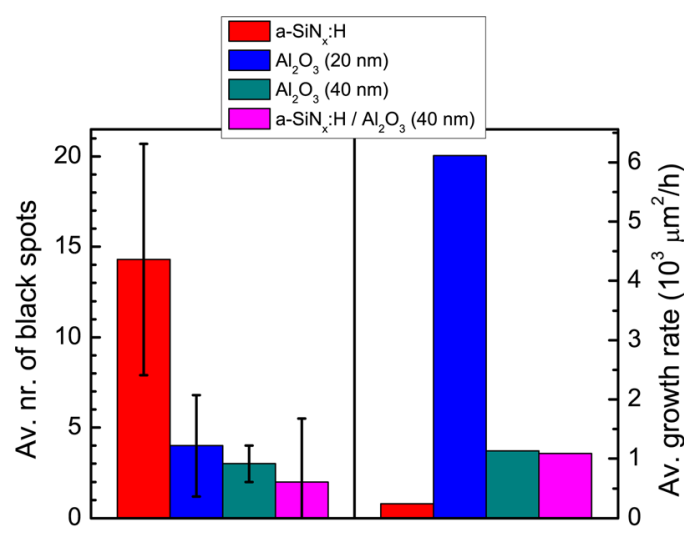

(a)

(b)

FIG. 4. (Color online) (a) Average number of black spots per OLED and (b) the average growth rates per black spot as measured by electroluminescence on OLED samples encapsulated with $300 \mathrm{~nm} \mathrm{a}_{-} \mathrm{SiN}_{\mathrm{x}}: \mathrm{H}, 40$ and $20 \mathrm{~nm}$ $\mathrm{Al}_{2} \mathrm{O}_{3}$. Results for a stack of a-SiN $\mathrm{x}: \mathrm{H}(300 \mathrm{~nm})$ and $\mathrm{Al}_{2} \mathrm{O}_{3}(40 \mathrm{~nm})$ are given as well. The barrier films have been deposited on the cathode of the OLED. The samples have been kept at $20^{\circ} \mathrm{C} / 50 \% \mathrm{RH}$ for 114 days and have only been removed to perform the electroluminescence measurements. The error bars for the average growth rates are estimated to be $\sim 100 \%$ of the measured value. 
defects uncovered and, on the basis of this result, the deposition of the stacks (see Sec. III C) has been carried out only with the $40 \mathrm{~nm}$ thick $\mathrm{ALD} \mathrm{Al}_{2} \mathrm{O}_{3}$ films.

A large scatter has been found in the growth rate data and the error bars were estimated to be as large as the measured values. From previous experiments we have learned that the number of particles can vary from batch to batch (a batch is a series of four glass plates, each with nine OLEDs) and even from plate to plate, which is the main reason for the scatter in the data. We note therefore that we only compared samples within one batch in order to limit the spread in particle density. To cancel the effects of the plate-to-plate variation each barrier has been prepared on nine OLEDs distributed over three plates as discussed in Sec. II. When the number of defects in the barriers became low due to the improvement of the encapsulation it became more challenging to get statistics from the experiments.

\section{Film stacks for OLED encapsulation}

To investigate the impact of the stacks on the OLED performance in terms of defect encapsulation, several stacks were prepared and compared. In these stacks the inorganic $\mathrm{Al}_{2} \mathrm{O}_{3}(40 \mathrm{~nm})$ and $\mathrm{a}-\mathrm{SiN}_{\mathrm{x}}: \mathrm{H}(300 \mathrm{~nm})$ layers were included, and an acrylate-based organic layer was introduced as well. This organic layer had negligible barrier properties but it served as mechanical protection of the device when applied as top layer. It could also generate a delay in water vapor permeation when applied as interlayer between inorganic layers (see Sec. I).

As already shown in Fig. 4, a stack of a-SiN ${ }_{\mathrm{x}}: \mathrm{H}$ and $\mathrm{Al}_{2} \mathrm{O}_{3}$ $\left(\mathrm{Al}_{2} \mathrm{O}_{3}\right.$ on top) neither reduced the number of black spots to a significant extent, nor significantly affected the growth rate of the black spots. Therefore in Fig. 5 a more extensive comparison has been made between various stack structures in terms of average number of black spots focusing on the case where the $\mathrm{Al}_{2} \mathrm{O}_{3}$ was applied first. With an average of only 3.6 black spots per device (active area is $6 \mathrm{~cm}^{2}$ ) the a-SiN $\mathrm{x}: \mathrm{H}$ encapsulation in this specific batch of OLEDs performed extremely well. Usually, the a-SiN $\mathrm{x}: \mathrm{H}$ barrier has between 10 and 15

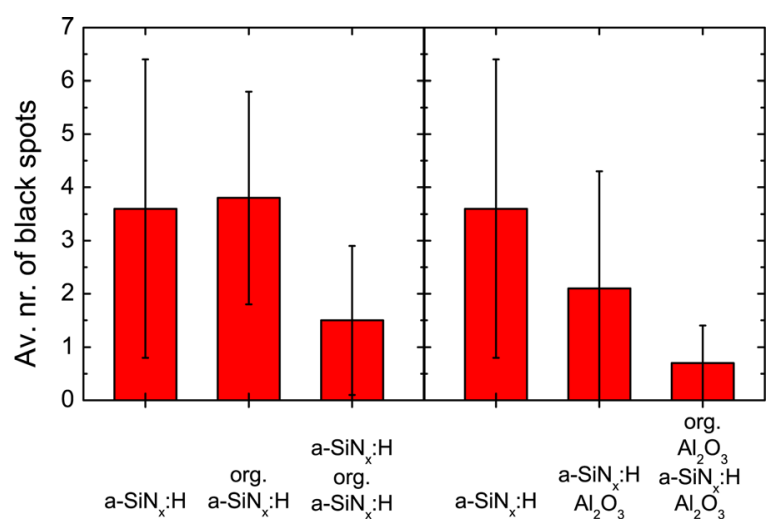

FIG. 5. (Color online) Average number of defects per OLED for several stacks that combine $300 \mathrm{~nm}$ of a-SiN $\mathrm{x}: \mathrm{H}$ deposited by PE-CVD, $40 \mathrm{~nm}$ $\mathrm{Al}_{2} \mathrm{O}_{3}$ prepared by PE-ALD, and organic (org.) layers. The samples have been kept at $20^{\circ} \mathrm{C} / 50 \% \mathrm{RH}$ for 158 days and have only been removed to perform the electroluminescence measurements. black spots per OLED, as shown in Fig. 4(a). This quality of the $\mathrm{a}-\mathrm{SiN}_{\mathrm{x}}: \mathrm{H}$ encapsulation was not reproduced in any of the other batches. Although the a-SiN $\mathrm{x}: \mathrm{H}$ film was of exceptional quality, applying first a $40 \mathrm{~nm} \mathrm{ALD} \mathrm{Al}_{2} \mathrm{O}_{3}$ layer on the cathode reduced the average number of defects by a factor of two (see Fig. 5, right side). Expanding the $\mathrm{Al}_{2} \mathrm{O}_{3}$ and $\mathrm{a}-\mathrm{SiN}_{\mathrm{x}}: \mathrm{H}$ film stack with extra layers decreased the amount of pinholes even further. This was best evidenced by results obtained for an $\mathrm{Al}_{2} \mathrm{O}_{3} / \mathrm{a}-\mathrm{SiN}_{\mathrm{x}}: \mathrm{H} / \mathrm{Al}_{2} \mathrm{O}_{3} /$ organic stack. This stack revealed an average of only 0.7 black spots per OLED, which corresponds to 0.12 black spots per $\mathrm{cm}^{2}$. The beneficial effect of stacking $\mathrm{ALD} \mathrm{Al}_{2} \mathrm{O}_{3}$ and $\mathrm{PE}-\mathrm{CVD}$ a-SiN $\mathrm{x}$ : $\mathrm{H}$ layers have been reported before by Carcia et al., ${ }^{10}$ but they indicated that their test values were limited by the epoxy which they used to glue the samples to the calcium substrates.

We note that the application of an organic layer on top of this stack structure did not have a beneficial effect, as can be concluded from the comparison between the single a-SiN ${ }_{x}: H$ layer and the $\mathrm{a}-\mathrm{SiN} \mathrm{N}_{\mathrm{x}}: \mathrm{H}$ covered by the organic layer (see Fig. 5, left side). However, when the organic layer was applied as interlayer between $\mathrm{a}-\mathrm{SiN}_{\mathrm{x}}: \mathrm{H}$ layers (i.e., a-SiN $\mathrm{x}: \mathrm{H}$ /organic/a-SiN $\mathrm{x}: \mathrm{H}$ ), it did show a decrease in the amount of black spots. This reduction can be attributed to the decoupling of the defects in the two inorganic layers leading to a time delay in the appearance of black spots during the electroluminescence measurements. In this case the delay was large enough such that fewer black spots appeared in the timeframe of the measurement. This is therefore also considered a promising approach that can also be pursued for $\mathrm{ALD} \mathrm{Al}_{2} \mathrm{O}_{3}$ as inorganic layer. Similar positive effects of building a barrier stack of inorganic and organic layers have been discussed in several articles, ${ }^{18,27,28}$ but few authors report on barrier films deposited directly on the cathode of the OLEDs. ${ }^{4,24}$

\section{CONCLUSIONS}

The water vapor permeation barrier properties of 20 and $40 \mathrm{~nm}$ thick $\mathrm{Al}_{2} \mathrm{O}_{3}$ films prepared by PE-ALD have been investigated with respect to the encapsulation of OLED devices and compared to a $300 \mathrm{~nm}$ thick PE-CVD a-SiN ${ }_{\mathrm{x}}: \mathrm{H}$ film as reference. The layers revealed an excellent intrinsic WVTR in the range of $10^{-6} \mathrm{~g} \mathrm{~m}^{-2}$ day $^{-1}$. However, with a WVTR of $2 \times 10^{-6} \mathrm{~g} \mathrm{~m}^{-2}$ day $^{-1}$ the PE-ALD layers outperformed the PE-CVD a-SiN ${ }_{\mathrm{x}}: \mathrm{H}$, particularly considering the one order of magnitude smaller film thickness of the $\mathrm{Al}_{2} \mathrm{O}_{3}$ layers.

The encapsulation of defects present at the cathode surface of the OLED has also been investigated for both materials. The OLED encapsulated by PE-ALD $\mathrm{Al}_{2} \mathrm{O}_{3}$ films showed on average 3-4 black spots per device on a $6 \mathrm{~cm}^{2}$ active area, which was 4 times lower than the devices encapsulated by PE-CVD a-SiN $\mathrm{X}_{\mathrm{x}} \mathrm{H}$ films. This result is remarkable considering that the PE-ALD layers are much thinner than the PE-CVD a-SiN $\mathrm{N}_{\mathrm{x}}$ :H films. It demonstrates that the ALD layer is beneficial for the encapsulation of particles present on the cathode of an OLED, most likely due to the 3D conformal growth of the ALD films. 
By stacking the inorganic barrier films we have shown that it is possible to reduce the number of defects in the encapsulation even further. The best result in our experiments was a defect density of 0.12 defects per $\mathrm{cm}^{2}$, which has been obtained for barriers with three inorganic layers $\left(\mathrm{Al}_{2} \mathrm{O}_{3} / \mathrm{a}-\mathrm{SiN}_{\mathrm{x}}: \mathrm{H} / \mathrm{Al}_{2} \mathrm{O}_{3}\right)$ and an organic layer on top. From other experiments it was found that the organic layer as top layer did not improve the encapsulation, which means that the reduction of the number of defects can be fully attributed to the inorganic layers in the stack. By adopting the organic layer as interlayer between inorganic layers prepared by ALD, it is expected that defect encapsulation and defect decoupling can effectively be combined and therefore be the key to a defect free barrier.

\section{ACKNOWLEDGMENTS}

This work was funded by the Netherlands Technology Foundation STW. The OLED samples were processed by T. Bernards and his crew in the Philips MiPlaza OLED prepilot line. The black spot measurements were performed by M. Meulendijk in the Reliability Centre of Philips MiPlaza, supervised by M. Kuilder. The experimental and technical support by E. Langereis and J. J. A. Zeebregts are gratefully acknowledged.

${ }^{1}$ P. E. Burrows, G. L. Graff, M. E. Gross, P. M. Martin, M. K. Shi, M. Hall, E. Mast, C. Bonham, W. Bennett, and M. B. Sullivan, Displays 22, 65 (2001).

${ }^{2}$ F. J. H. van Assche, R. T. Vangheluwe, J. W. C. Maes, W. S. Mischke, M. D. Bijker, F. C. Dings, M. F. J. Evers, W. M. M. Kessels, and M. C. M. van de Sanden, Proc. Soc. Inf. Displays 695 (2004).

${ }^{3}$ J. S. Lewis and M. S. Weaver, IEEE J. Sel. Top. Quantum Electron. 10, 1 (2004).

${ }^{4}$ A. M. B. van Mol, P. van de Weijer, and C. Tanase, Proc. SPIE 6999, 46 (2008).

${ }^{5}$ C. W. T. Bulle-Lieuwma and P. van de Weijer, Appl. Surf. Sci. 252, 6597 (2006).

${ }^{6}$ J. H. Burroughes, D. D. C. Bradley, A. R. Brown, R. N. Marks, K. Mackay, R. H. Friend, P. L. Burns, and A. B. Holmes, Nature 347, 539 (1990).

${ }^{7}$ S. M. George, Chem. Rev. 110, 111 (2010).
${ }^{8}$ H.B. Profijt, S. E. Potts, M. C. M. van de Sanden, and W. M. M. Kessels, J. Vac. Sci. Technol. A 29, 050801 (2011).

${ }^{9}$ S. B. S. Heil, J. L. van Hemmen, M. C. M. van de Sanden, and W. M. M. Kessels, J. Appl. Phys. 103, 103302 (2008).

${ }^{10}$ P. F. Carcia, R. S. McLean, M. D. Groner, A. A. Dameron, and S. M. George, J. Appl. Phys. 106, 023533 (2009).

${ }^{11}$ A. A. Dameron, S. D. Davidson, B. B. Burton, P. F. Carcia, R. S. McLean, and S. M. George, J. Phys. Chem. C 112, 4573 (2008).

${ }^{12}$ E. Langereis, M. Creatore, S. B. S. Heil, M. C. M. Van de Sanden, and W. M. M. Kessels, Appl. Phys. Lett. 89, 081915 (2006).

${ }^{13}$ A. P. Ghosh, L. J. Gerenser, C. M. Jarman, and J. E. Fornalik, Appl. Phys. Lett. 86, 223503 (2005).

${ }^{14}$ J. Meyer, D. Schneidenbach, T. Winkler, S. Hamwi, T. Weimann, P. Hinze, S. Ammermann, H. -H. Johannes, T. Riedl, and W. Kowalsky, Appl. Phys. Lett. 94, 233305 (2009).

${ }^{15}$ M. D. Groner, S. M. George, R. S. McLean, and P. F. Carcia, Appl. Phys. Lett. 88, 051907 (2006).

${ }^{16}$ S. H. K. Park, J. Oh, C. S. Hwang, J. I. Lee, Y. S. Yang, and H. Y. Chu, Electrochem. Solid-State Lett. 8, H21 (2005).

${ }^{17}$ C. Y. Chang, C. T. Chou, Y. J. Lee, M. J. Chen, and F. Y. Tsai, Org. Electron. 10, 1300 (2009).

${ }^{18}$ G. L. Graff, R. E. Williford, and P. E. Burrows, J. Appl. Phys. 96, 1840 (2004).

${ }^{19}$ J. L. van Hemmen, S. B. S. Heil, J. H. Klootwijk, F. Roozeboom, C. J. Hodson, M. C. M. van de Sanden, and W. M. M. Kessels, J. Electrochem. Soc. 154, G165 (2007).

${ }^{20}$ S. E. Potts, W. Keuning, E. Langereis, G. Dingemans, M. C. M. van de Sanden, and W. M. M. Kessels, J. Electrochem. Soc. 157, P66 (2010).

${ }^{21}$ E. Langereis, J. Keijmel, M. C. M. van de Sanden, and W. M. M. Kessels, Appl. Phys. Lett. 92, 231904 (2008).

${ }^{22}$ G. Nisato, P. Bouten, P. Slikkerveer, W. Bennett, G. Graf, N. Rutherford, and L. Wiese, Proc. Asia Display 1435 (2001).

${ }^{23}$ G. Nisato, M. Kuilder, P. Bouten, L. Moro, O. Philips, and N. Rutherford, SID Int. Symp. Dig. Technol. 34, 550 (2003).

${ }^{24}$ P. van de Weijer, G. Rietjens, C. Tanase, H. Lifka, J. Michels, F. J. H. van Assche, and T. van Mol, Proceedings of OSC, 2008 (unpublished).

${ }^{25}$ J. Meyer, P. Görrn, F. Bertram, S. Hamwi, T. Winkler, H.-H. Johannes, T. Weimann, P. Hinze, T. Riedl, and W. Kowalsky, Adv. Mater. 21, 1845 (2009).

${ }^{26}$ P. F. Carcia, R. S. McLean, M. H. Reilly, M. D. Groner, and S. M. George, Appl. Phys. Lett. 89, 031915 (2006).

${ }^{27}$ M. Schaepkens, T. W. Kim, A. G. Erlat, M. Yan, K. W. Flanagan, C. M. Heller, and P. A. McConnellee, J. Vac. Sci. Technol. A 22, 1716 (2004).

${ }^{28}$ T. W. Kim, M. Yan, A. G. Erlat, P. A. McConnelee, M. Pellow, J. Deluca, T. P. Feist, A. R. Duggal, and M. Schaepkens, J. Vac. Sci. Technol. A 23, 971 (2005). 